\title{
Linkage studies of catechol-O-methyltransferase (COMT) and dopamine-beta-hydroxylase $(D B H)$ cDNA expression levels
} Chao Xing $1,2,3$, Monica Torres-Caban ${ }^{1}$, Tao Wang ${ }^{1}$, Qing Lu ${ }^{1}$, Guan Xing ${ }^{1}$ and Robert C Elston*1

Address: ${ }^{1}$ Department of Epidemiology and Biostatistics, Case Western Reserve University, Wolstein Research Building 2103, Cornell Drive, Cleveland, Ohio 44106, USA, ${ }^{2}$ Department of Clinical Sciences, University of Texas Southwestern Medical Center, 5323 Harry Hines Boulevard, Dallas, Texas 75390-8591, USA and ${ }^{3}$ McDermott Center for Human Growth and Development, University of Texas Southwestern Medical Center, 5323 Harry Hines Boulevard, Dallas, Texas 75390-8591, USA

Email: Chao Xing - chao.xing@utsouthwestern.edu; Monica Torres-Caban - monica.torres-caban@case.edu; Tao Wang - tao.wang@case.edu; Qing Lu - qing.lu@case.edu; Guan Xing - guan.xing@bms.com; Robert C Elston* - rce@darwin.case.edu

* Corresponding author

from Genetic Analysis Workshop 15

St. Pete Beach, Florida, USA. II-I5 November 2006

Published: 18 December 2007

BMC Proceedings 2007, I(Suppl I):S95

This article is available from: http://www.biomedcentral.com/I753-656I/I/SI/S95

(c) 2007 Xing et al; licensee BioMed Central Ltd.

This is an open access article distributed under the terms of the Creative Commons Attribution License (http://creativecommons.org/licenses/by/2.0), which permits unrestricted use, distribution, and reproduction in any medium, provided the original work is properly cited.

\begin{abstract}
The COMT and DBH genes are physically located at chromosomes $22 \mathrm{qI}$ I and $9 \mathrm{q} 34$, respectively, and both COMT and $D B H$ are involved in catecholamine metabolism and are strong candidates for certain psychiatric and neurological disorders. Although the genetic determinants for both enzymes' activities have been widely studied, their genetic involvement on gene mRNA expression levels remains unclear. In this study we performed quantitative linkage analysis of COMT and DBH cDNA expression levels, identifying transcriptional regulatory regions for both genes. Multiple Haseman-Elston regression was used to detect both additive and interactive effects between two loci. We found that the master transcriptional regulatory region $20 \mathrm{q} / 3$ had an additive effect on the COMT expression level. We also found that chromosome $19 \mathrm{p} / 3$ showed both additive and interactive effects with $9 \mathrm{q} 34$ on $D B H$ expression level. Furthermore, a potential interaction between COMT and $D B H$ was indicated.
\end{abstract}

\section{Background}

Catechol-O-methyltransferase (COMT) (MIM 116790) catalyzes the transfer of a methyl group from S-adenosylmethionine to catecholamines [1], and dopamine-betahydroxylase (DBH) (MIM 223360) catalyzes the conversion of dopamine to norepinephrine [2]; both enzymes are involved in the catecholamine metabolism system, in which abnormalities are hypothesized to be related to the development of psychiatric and neurological disorders such as schizophrenia and depression (for reviews, see $[3,4])$. There are two distinct forms of COMT, a membrane-bound COMT (MB-COMT) and a soluble COMT (S-COMT) found in the cell cytoplasm [5]; the former is predominantly expressed in brain neurons, whereas the latter is predominantly expressed in other tissues such as liver and kidney. DBH is expressed in the vesicles of central noradrenergic and adrenergic neurons, peripheral noradrenergic neurons, and adrenomedullary neuron- 
secreotry cells [6]. The COMT and DBH genes are physically located at chromosomes 22q11 and 9q34, respectively $[7,8]$.

There has been intensive research on the genetic determinants of plasma COMT and DBH activities, and findings so far strongly suggest that the structural genes COMT and $D B H$ encoding these proteins are the major quantitative trait loci for their respective plasma activities; moreover, in both genes single-nucleotide polymorphisms (SNPs) have been identified that may account for most of the variation in the enzyme activity levels. On the common functional SNP rs165688, a G $\rightarrow$ A substitution in exon 4 of COMT produces a valine $\rightarrow$ methionine (Val/Met) substitution at codons 158 and 108 in the MB-COMT and SCOMT transcripts, respectively. This polymorphism has been shown to have a functional effect on enzyme activity; in particular, Val is a predominant factor that determines higher COMT activity [9]. The SNP rs1611115 ($1021 \mathrm{C} \rightarrow \mathrm{T}$ ) located in the $5^{\prime}$ flanking region of the $D B H$ gene accounts for $35 \%$ to $52 \%$ of the variance in plasma DBH activity in populations from diverse geographic origins [10].

Though the major effects of these common variants on enzyme activities have been replicated in independent samples, their effects on gene mRNA expression levels remain unclear. The effect of SNP rs165688 on COMT mRNA expression level has been controversial. Bray et al. [11] showed that it altered the COMT mRNA expression level; in contrast, several other studies failed to detect this association between COMT genotypes and expression level (for examples, see [12]). So far, studies on the determinants of COMT expression level have been limited to seeking cis-acting regulators, including SNP rs 165688 and several other SNPs within COMT. To our knowledge, there is as yet no literature documenting effects of SNPs on $D B H$ mRNA expression levels.

Phenotypic variation in the transcript level represents an intermediate stage between DNA sequence differences and the clinical expression of complex traits, and there have been studies suggesting a genetic contribution to the variation in gene expression level [13-15]. In the current study, we performed quantitative linkage analysis for both $C O M T$ and $D B H$ expression phenotypes, identifying transcriptional regulatory regions for both genes. For COMT, we first identified cis-acting influences on the gene expression level, and then we performed a genome-wide linkage scan for trans-acting regulators across the genome conditional on the cis-acting effect at chromosome 22q11. For $\mathrm{DBH}$, we similarly first identified the cis-acting influences on the gene expression level, and then, both conditional and unconditional on the cis-acting effect at chromosome 9q34, performed a linkage scan for trans-acting regulators specifically on chromosome 19 , based on the evidence from previous linkage studies [16-18] that there might be a second locus near chromosome 19p13 acting jointly with $D B H$ at chromosome 9q34 to influence DBH plasma activity.

\section{Methods}

The study subjects consisted of 14 three-generation CEPH (Centre d'Etude du Polymorphisme Humain) Utah pedigrees, including 371 full sibling pairs. 2,820 SNPs were relatively evenly genotyped across the 22 autosomes by the SNP Consortium [19]. Treating the expression level of COMT and $D B H$ in lymphoblastoid cells of the above subjects as a quantitative trait, we applied HasemanElston regression model-free linkage analyses [20,21], as implemented in the SIBPAL program. In particular, only data on sib pairs were considered (thus avoiding the complication of possible intergenerational heterogeneity) and the generalized estimating equation technique [22] was utilized to allow for non-independence of sib pairs within a sibship. The basic Haseman-Elston (HE) regression can be written in the form

$$
Y=\beta_{0}+\beta_{1} \hat{\pi}_{i}
$$

where $Y$ is a function of traits for a sib pair, $\hat{\pi}_{i}$ is the estimated proportion of alleles shared identically by descent (IBD) at marker locus $i$ between members of a sib pair, $\beta_{0}$ is the intercept, and $\beta_{1}$, the slope, is the locus-specific genetic variance of the trait attenuated by recombination between the trait and marker loci. To detect trans-acting effects at other genomic regions conditional on the cis-acting effect at the structural gene loci $(22 \mathrm{q} 11$ and $9 \mathrm{q} 34$ for $C O M T$ and $D B H$, respectively), we performed the multiple HE regression

$$
Y=\beta_{0}+\beta_{1} \hat{\pi}_{0}+\lambda \hat{\pi}_{1}
$$

where the subscript 0 denotes a marker for the structural gene locus and the subscript 1 denotes another locus in the genome. The coefficient $\lambda$ denotes the (attenuated) genetic variance at locus 1 and a value significantly different from zero indicates an additive effect of locus 1 with locus 0 on gene expression level. We further investigated genetic interaction between the structural gene locus and the other locus with the model

$$
Y=\beta_{0}+\beta_{1} \hat{\pi}_{0}+\beta_{2} \hat{\pi}_{1}+\gamma \hat{\pi}_{0} \hat{\pi}_{1}
$$

where $\gamma$ denotes variance (again, attenuated by recombination) due to the genetic interaction between locus 1 and locus 0 , and a value significantly different from zero indicates an interactive effect of the two loci on gene expres- 
Table I: Chromosome regions showing only additive trans-acting effects ${ }^{\mathrm{a}}$ with $22 \mathrm{q}$ I on COMT expression level

\begin{tabular}{|c|c|c|c|}
\hline Genomic region & Closest marker & Physical distance (Mb) & $p$-Value for $\lambda$ \\
\hline $3 q 26$ & rsl4998I2 & 173.2 & $4.4 \times 10^{-3}$ \\
\hline $4 q 35$ & rs1979255 & 190.7 & $3.4 \times 10^{-4}$ \\
\hline $5 q 34$ & rs 1387395 & 163.8 & $4.1 \times 10^{-3}$ \\
\hline $6 p 22$ & rs 1475149 & 21.8 & $2.5 \times 10^{-3}$ \\
\hline $7 p 21$ & rs988418 & 9.9 & $3.7 \times 10^{-3}$ \\
\hline $8 q 22$ & rs 1075394 & 101.5 & $1.8 \times 10^{-3}$ \\
\hline $9 q 34$ & rs936249 & 138.2 & $2.2 \times 10^{-3}$ \\
\hline $10 p \mid 1$ & rs 1857063 & 29.4 & $2.0 \times 10^{-7}$ \\
\hline$|8 p| \mid$ & rs321663 & 8.6 & $2.1 \times 10^{-4}$ \\
\hline $20 q 13$ & rs756529 & 47.4 & $3.1 \times 10^{-3}$ \\
\hline
\end{tabular}

aAt a nominal level of 0.005

sion level. Single-point IBD sharing was estimated by the program GENIBD. Both of the above programs are included in the Statistical Analysis for Genetic Epidemiology (S.A.G.E.) software [23].

\section{Results}

\section{Linkage of COMT expression levels}

We detected a linkage signal at chromosome 22q11 ( $p=$ $\left.6.5 \times 10^{-3}\right)$. The closest SNP to the peak of the signal is rs738842, which is $\sim 3$ megabases $(\mathrm{Mb})$ centrometric to the COMT gene and within the cis-acting region defined by Morley et al. [15]. There were 10 regions showing only additive trans-acting effects (Table 1 ) and 7 regions showing only interactive trans-acting effects (Table 2) at the nominal significance level of 0.005 ; at 14 other regions, both effects attained a nominal significance level of 0.05 and at least one attained the level 0.005 (Table 3). These nominal significance levels were arbitrarily chosen in order to report the most notable results. Note that 1 ) chromosome 9q34, where $D B H$ is located, showed an additive trans-acting effect with 22q11 on COMT expression level; and 2) chromosome 20q13, which was one of the two hot spots of transcriptional regulation detected by Morley et al. [15], was also detected to have an additive effect with 22q11 on the COMT expression level.

\section{Linkage of DBH expression levels}

There was no linkage signal for the DBH expression level at either chromosome $9 \mathrm{q} 34$ or chromosome 19p13 when analyzing all of the 14 pedigrees together. There could be many reasons for the lack of any linkage signal at chromosome 9q34, the structural gene location (see Discussion). However, upon analyzing the pedigrees individually, it was noticed that three pedigrees (1340, 1345 and 1318), which included 70 full sibling pairs, showed a positive linkage signal at 9q34. Because our primary interest was to test whether there is a second locus near chromosome 19 p13 related to $D B H$, in addition to the $D B H$ gene, we selected these three pedigrees for further study and found that a linkage signal at $19 \mathrm{p} 13$ then also emerged, showing both additive and interactive trans-acting effects $(p=2.4 \times$ $10^{-2}$ and $p=2.6 \times 10^{-2}$, respectively) with the locus at chromosome 9q34 on DBH expression level (Fig. 1).

\section{Discussion}

Phenotypic variation in the transcript level of a gene involves genetic components; however, the transcriptional regulatory elements may or may not lie in the structural gene itself. Studies by Morley et al. [15] have suggested the existence of master regulatory regions, and we identified chromosome 20q13, nominated by them, as regulating COMT expression level. Note that Morley et al. [15] performed simple HE regression, while we performed multiple HE regression so as to condition on the

Table 2: Chromosome regions showing only interactive trans-acting effects ${ }^{\mathrm{a}}$ with $22 \mathrm{q}$ I I on COMT expression level

\begin{tabular}{|c|c|c|c|}
\hline Genomic region & Closest marker & Physical distance (Mb) & $p$-Value for $\gamma$ \\
\hline Iq32 & rs87|446 & 196.9 & $1.9 \times 10^{-3}$ \\
\hline $3 p 26$ & rs 1385466 & 4.0 & $1.2 \times 10^{-5}$ \\
\hline $6 q 23$ & rs2040034 & 137.3 & $3.9 \times 10^{-4}$ \\
\hline $9 q 33$ & rs|326808 & 116.7 & $2.1 \times 10^{-3}$ \\
\hline $10 q 22$ & rs1907308 & 78.0 & $8.3 \times 10^{-6}$ \\
\hline $15 q 26$ & rs288423 & 96.0 & $3.3 \times 10^{-3}$ \\
\hline$|8 q 2|$ & rs1943985 & 45.5 & $1.5 \times 10^{-4}$ \\
\hline
\end{tabular}

${ }^{a}$ At a nominal level of 0.005 
Table 3: Chromosome regions showing both additive and interactive trans-acting effects ${ }^{\mathrm{a}}$ with $22 \mathrm{q}$ I I on COMT expression level

\begin{tabular}{|c|c|c|c|c|}
\hline \multirow[b]{2}{*}{ Genomic region } & \multirow[b]{2}{*}{ Closest marker } & \multirow[b]{2}{*}{ Physical distance (Mb) } & \multicolumn{2}{|c|}{$p$-Value } \\
\hline & & & $\lambda$ & $\gamma$ \\
\hline$|q 4|$ & rs156II89 & 213.5 & $1.1 \times 10^{-4}$ & $4.6 \times 10^{-3}$ \\
\hline $2 q 35$ & rs 1425118 & 216.8 & $<1.0 \times 10^{-8}$ & $3.5 \times 10^{-2}$ \\
\hline $3 q 28$ & rs 1559018 & 191.8 & $2.3 \times 10^{-2}$ & $2.9 \times 10^{-5}$ \\
\hline $4 q 31$ & rs795995 & $14||$. & $1.5 \times 10^{-3}$ & $5.0 \times 10^{-7}$ \\
\hline $5 q 14$ & rs1020720 & 80.5 & $1.7 \times 10^{-2}$ & $1.8 \times 10^{-3}$ \\
\hline $6 q 16$ & rs2021678 & 102.1 & $1.1 \times 10^{-3}$ & $4.7 \times 10^{-2}$ \\
\hline $7 p 14$ & rs2051936 & 40.8 & $5.7 \times 10^{-3}$ & $3.5 \times 10^{-3}$ \\
\hline $8 p 23$ & rs433960 & 12.9 & $4.7 \times 10^{-2}$ & $2.9 \times 10^{-5}$ \\
\hline $9 p 23$ & rs|4|2307 & 13.0 & $1.3 \times 10^{-4}$ & $6.6 \times 10^{-3}$ \\
\hline $14 q 13$ & rsl983667 & 36.2 & $1.4 \times 10^{-4}$ & $1.1 \times 10^{-2}$ \\
\hline $16 p 13$ & rs1981492 & 0.3 & $1.0 \times 10^{-3}$ & $5.9 \times 10^{-3}$ \\
\hline $16 q 24$ & rs880275 & 84.8 & $4.7 \times 10^{-3}$ & $2.6 \times 10^{-3}$ \\
\hline $17 p 12$ & rs433068 & 15.2 & $4.8 \times 10^{-2}$ & $4.4 \times 10^{-3}$ \\
\hline $22 q 13$ & rs960362 & 47.4 & $4.8 \times 10^{-4}$ & $8.6 \times 10^{-3}$ \\
\hline
\end{tabular}

aBoth effects attained a nominal significance level of 0.05 and at least one reached the level 0.005 .

IBD sharing at COMT, i.e., our analysis refined their original investigation and provided further evidence supporting chromosome $20 \mathrm{q} 13$ as a regulatory region. In the current data, overall there was a linkage signal at $22 \mathrm{q} 11$ for COMT expression level, but no signal at 9q34 for $D B H$ expression level. Lack of an overall linkage signal at 9q34 for $D B H$ could be due to there not being enough $D B H$ polymorphism segregation in the sample, to there being less expression variation among individuals than between replicates within an individuals [15], from low levels of transcript abundance in view of its tissue-specific expres- sion pattern (Dr. Joseph F. Cubells, personal communication), or to genetic heterogeneity, as also indicated in the earlier study of plasma DBH activity [16].

In this study we employed multiple HE regression to detect additive and interactive effects between two loci. In the three pedigrees selected for having a positive linkage signal at 9q34 for $D B H$ expression level, we detected a boost of signal at chromosome 19p13, where previous studies [16-18] indicated the existence of a locus influencing DBH plasma activity. The multiple HE regression indi-
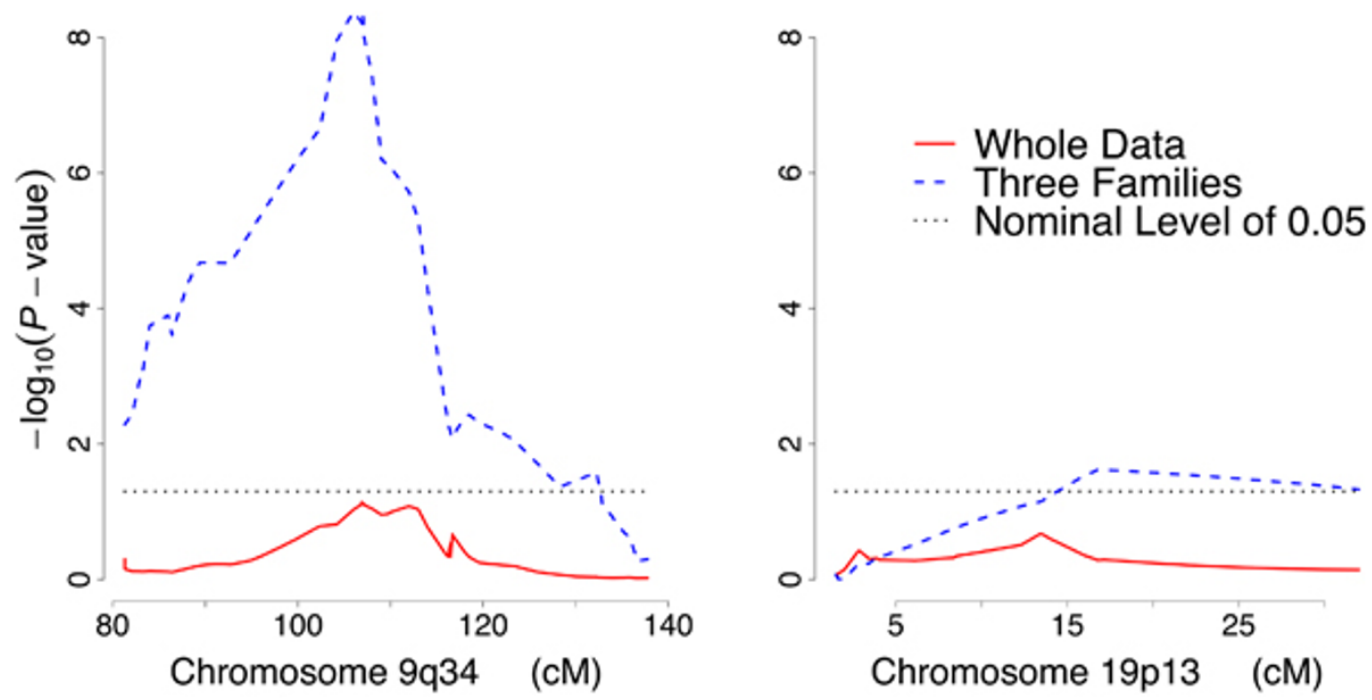

Figure I

Linkage signals of $D B H$ expression levels at chromosomes $9 q 34$ and $19 p / 3$. 
cated both additive and interactive effects of the two loci, suggesting epistasis between them. For simplicity, and because of the limited amount of data available, we did not dissect the total genetic variance into additive and dominance components in this study; with more data the interaction could be characterized by more elaborate models [24], and even embedded in a general pedigree framework $[25,26]$. We also noticed that chromosome $9 q 34$, where $D B H$ is located, showed an additive trans-acting effect with 22q11 on COMT expression level. This is not totally unexpected because both enzymes are involved in catecholamine metabolism; however, we could not find in the literature any genetic study on the interaction between them, which is surprising. Interaction between COMT and $D B H$ could be a potential research topic.

In summary, we performed quantitative linkage analysis for both COMT and DBH expression phenotypes, identifying transcriptional regulatory regions for both genes. Multiple HE regression was used to detect additive and interactive effects between two loci. The master transcriptional regulatory region $20 \mathrm{q} 13$ had an additive effect on the COMT expression level. Chromosome regions 9q34 and 19p13 acted epistatically on $\mathrm{DBH}$ expression level. Potential interaction between COMT and $D B H$ was indicated.

\section{Competing interests}

The author(s) declare that they have no competing interests.

\section{Acknowledgements}

Some of the results in this paper were obtained by using the program package S.A.G.E., which is supported by a U.S. Public Health Service Resource Grant (RR03655) from the National Center for Research Resources. This work was supported in part by research grants GM-28356 from the National Institute of General Medical Sciences, Cancer Center Support Grant P30CAD43703 from the National Cancer Institute, and a Training grant (HL07567) from the National Heart, Lung and Blood Institute. CX was supported by a Merck Foundation fellowship. CX and QL were sponsored to attend GAWI5 by the Endowment Sponsored Mentorship Program of Case Western Reserve University Graduate School.

This article has been published as part of BMC Proceedings Volume I Supplement I, 2007: Genetic Analysis Workshop 15: Gene Expression Analysis and Approaches to Detecting Multiple Functional Loci. The full contents of the supplement are available online at http://www.biomedcentral.com/ |753-6561/I?issue=SI.

\section{References}

I. Axelrod J, Tomchick R: Enzymatic O-methylation of epinephrine and other catechols. J Biol Chem 1958, 233:702-705.

2. Kaufman S, Friedman S: Dopamine-beta-hydroxylase. Pharmacol $\operatorname{Rev} 1965,17: 71-100$.

3. Gogos JA, Gerber DJ: Schizophrenia susceptibility genes: emergence of positional candidates and future directions. Trends Pharmacol Sci 2006, 27:226-233.

4. Cubells JF, Zabetian CP: Human genetics of plasma dopamine beta hydroxylase activity: application to research in psychiatry and neurology. Psychopharmacology (Berl) 2004, 174:463-476.
5. Tenhunen J, Salminen M, Jalanko A, Ukkonen S, Ulmanen I: Structure of the rat catechol-O-methyltransferase gene: separate promoters are used to produce mRNAs for soluble and membrane-bound forms of the enzyme. DNA Cell Biol 1993, I 2:253-263.

6. Kemper CM, O'Connor DT, Westlund KN: Immunocytochemical localization of dopamine-beta-hydroxylase in neurons of the human brain stem. Neuroscience 1987, 23:98I-989.

7. Grossman MH, Emanuel BS, Budarf ML: Chromosomal mapping of the human catechol-O-methyltransferase gene to 22qI I.I-q I I.2. Genomics 1992, I 2:822-825.

8. Craig SP, Buckle V], Lamouroux A, Mallet J, Craig IW: Localization of the human dopamine beta hydroxylase $(D B H)$ gene to chromosome 9q34. Cytogenet Cell Genet 1988, 48:48-50.

9. Lotta T, Vidgren J, Tilgmann C, Ulmanen I, Melen K, Julkunen I, Taskinen J: Kinetics of human soluble and membrane-bound catechol-O-methyltransferase: a revised mechanism and description of the thermolabile variant of the enzyme. Biochemistry 1995, 34:4202-4210.

10. Zabetian CP, Anderson GM, Buxbaum SG, Elston RC, Ichinose H, Nagatsu T, Kim KS, Kim CH, Malison RT, Gelernter J, Cubells JF: A quantitative-trait analysis of human plasma-dopamine betahydroxylase activity: evidence for a major functional polymorphism at the DBH locus. Am J Hum Genet 200I, 68:5 I 5-522.

11. Bray NJ, Buckland PR, Williams NM, Williams HJ, Norton N, Owen MJ, O'Donovan MC: A haplotype implicated in schizophrenia susceptibility is associated with reduced COMT expression in human brain. Am J Hum Genet 2003, 73:152-16I.

12. Chen J, Lipska BK, Halim N, Ma QD, Matsumoto M, Melhem S, Kolachana BS, Hyde TM, Herman MM, Apud J, Egan MF, Kleinman JE, Weinberger DR: Functional analysis of genetic variation in catechol-O-methyltransferase (COMT): effects on mRNA, protein, and enzyme activity in postmortem human brain. $\mathrm{Am} J$ Hum Genet 2004, 75:807-82I.

13. Yan H, Yuan W, Velculescu VE, Vogelstein B, Kinzler KW: Allelic variation in human gene expression. Science 2002, 297: I 143.

14. Cheung VG, Conlin LK, Weber TM, Arcaro M, Jen KY, Morley M, Spielman RS: Natural variation in human gene expression assessed in lymphoblastoid cells. Nat Genet 2003, 33:422-425.

15. Morley M, Molony CM, Weber TM, Devlin JL, Ewens KG, Spielman RS, Cheung VG: Genetic analysis of genome-wide variation in human gene expression. Nature 2004, 430:743-747.

16. Wilson AF, Elston RC, Siervogel RM, Tran LD: Linkage of a gene regulating dopamine-beta-hydroxylase activity and the $A B O$ blood group locus. Am J Hum Genet 1988, 42:160-166.

17. Wilson AF, Elston RC, Sellers TA, Bailey-Wilson JE, Gersting JM, Deen DK, Sorant AJM, Tran LD, Amos CI, Siervogel RM: Stepwise oligogenic segregation and linkage analysis illustrated with dopamine-betahydroxylase activity. Am J Med Genet 1990, 35:425-432.

18. Province M: Sequential methods of analysis for genome scans. Adv Genet 200I, 42:499-5I4.

19. Matise TC, Sachidanandam R, Clark AG, Kruglyak L, Wijsman E, Kakol J, Buyske S, Chui B, Cohen P, de Toma C, Ehm M, Glanowski S, He C, Heil J, Markianos K, McMullen I, Pericak-Vance MA, Silbergleit A, Stein L, Wagner M, Wilson AF, Winick JD, Winn-Deen ES, Yamashiro CT, Cann HM, Lai E, Holden AL: A 3.9-centimorgan-resolution human single-nucleotide polymorphism linkage map and screening set. Am J Hum Genet 2003, 73:27I-284.

20. Haseman JK, Elston RC: The investigation of linkage between a quantitative trait and a marker locus. Behav Genet 1972, 2:3-19.

21 . Shete $S$, Jacobs KB, Elston RC: Adding further power to the Haseman and Elston method for detecting linkage in larger sibships: weighting sums and differences. Hum Hered 2003, 55:79-85.

22. Liang K-Y, Zeger SL: Longitudinal data analysis using generalized linear models. Biometrika 1986, 73:13-22.

23. S.A.G.E. Statistical analysis for genetic epidemiology. Version 5.2 [http://darwin.case.edu/sage]

24. Tiwari HK, Elston RC: Linkage of multilocus components of variance to polymorphic markers. Ann Hum Genet 1997, 61:253-261.

25. Wang T, Elston RC: Two-level Haseman-Elston regression for general pedigree data analysis. Genet Epidemiol 2005, 29:12-22.

26. Almasy L, Blangero J: Multipoint quantitative-trait linkage analysis in general pedigrees. Am J Hum Genet 1998, 62:1198-1211. 